IZA DP No. 5299

Charity as a Signal of Trustworthiness

Sebastian Fehrler

November 2010 


\title{
Charity as a Signal of Trustworthiness
}

\author{
Sebastian Fehrler \\ CIS (University of Zurich and ETH Zurich) \\ and IZA
}

\section{Discussion Paper No. 5299 \\ November 2010}

\author{
IZA \\ P.O. Box 7240 \\ 53072 Bonn \\ Germany \\ Phone: +49-228-3894-0 \\ Fax: +49-228-3894-180 \\ E-mail: iza@iza.org
}

\begin{abstract}
Any opinions expressed here are those of the author(s) and not those of IZA. Research published in this series may include views on policy, but the institute itself takes no institutional policy positions.

The Institute for the Study of Labor (IZA) in Bonn is a local and virtual international research center and a place of communication between science, politics and business. IZA is an independent nonprofit organization supported by Deutsche Post Foundation. The center is associated with the University of Bonn and offers a stimulating research environment through its international network, workshops and conferences, data service, project support, research visits and doctoral program. IZA engages in (i) original and internationally competitive research in all fields of labor economics, (ii) development of policy concepts, and (iii) dissemination of research results and concepts to the interested public.
\end{abstract}

IZA Discussion Papers often represent preliminary work and are circulated to encourage discussion. Citation of such a paper should account for its provisional character. A revised version may be available directly from the author. 
IZA Discussion Paper No. 5299

November 2010

\section{ABSTRACT}

\section{Charity as a Signal of Trustworthiness}

Being perceived as trustworthy comes with substantial economic benefits in many situations. Making other people think you are a trustworthy person may, therefore, be an important motive for charity and other forms of prosocial behavior, provided these activities work as signals of trustworthiness. This paper shows that donating money to an NGO substantially raises the other players' beliefs about the donors' trustworthiness in a simple trust game. Consequently, donors receive higher transfers. The magnitude of these benefits is substantial.

JEL Classification: $\quad$ C72, C92, H41

Keywords: charity, signaling, trust, trustworthiness

Corresponding author:

Sebastian Fehrler

University of Zurich

and Center for Comparative and International Studies (CIS)

Chair of Political Economy

Affolternstrasse 56

8050 Zurich

Switzerland

E-mail: sebastian.fehrler@pw.uzh.ch 


\section{Introduction}

The motives for charity and prosocial behavior in general have been studied widely. Various authors have developed theories with extrinsic, intrinsic, reputational and prestige motives (e.g., Harbaugh 1998, Bénabou and Tirole 2006), a motive of signaling wealth (Glazer and Konrad 1996), and theories of warm-glow (e.g., Andreoni 1990).

Bénabou and Tirole's (2006) and Ellingsen and Johannesson's (2008) models feature the reputation of being a prosocial person, and the social esteem that comes along with it, as an important motive for prosocial behavior. Indeed, several experimental studies show that many subjects care about the other subjects' perception of their prosociality (see, e.g., Ariely et al. 2009, Dana et al. 2006, Soetevent 2005, Andreoni and Petrie 2004, Rege and Telle 2004 or Gächter and Fehr 1999). In all these studies subjects act more prosocially, if their actions are observable by others than under privacy.

An incentive for building a reputation of being a prosocial person might be that prosocial people benefit from acts of indirect reciprocity (Alexander 1987, Nowak and Sigmund 1998). Milinski et al. (2002) and Albert et al. (2007) demonstrate that subjects in lab experiments, who publicly donate to an NGO, are treated better by other subjects than subjects who do not donate or donate little.

A potentially even more important channel through which subjects benefit from a reputation of prosociality might be that they are perceived as more trustworthy. It has been argued that costly signaling in the form of prosocial behavior could explain the evolution of cooperation (Gintis et al. 2001). In Gintis et al.'s model cooperative intent, which is obviously related to the concept of trustworthiness, is signaled by providing benefits to others. An equilibrium which separates cooperative from uncooperative people exists because cooperative people face lower costs for providing the benefits. An interesting experimental study in this context is Barclay and Willer (2007). In their main treatment, one subject observes two other subjects play a continuous prisoner's dilemma game, and then chooses one of the two players as a partner for the same game in a second round. Anticipating that cooperation in the first round increases the probability of being selected in the second round, the subjects in the first round cooperate substantially more than in a control treatment, in which partners are randomly matched in the second round. While this study indicates that cooperative behavior leads to a reputation of cooperative intent in the same type of situation, it does not indicate whether prosocial behavior in one situation can help to build a general reputation of trustworthiness that carries over to other situations.

Two further studies which investigate signals of trustworthiness are Diekmann and Przepi- 
orka (2008) and Bolle and Kaehler (2007). In both studies trust games are played with two types of trustees with different pay-offs to cooperation. Their type is unknown to trustors and they can signal their type by giving away gifts or by advertising (i.e., by burning money). Both studies find that subjects make use of the signal and this leads others to trust them more.

The question this paper addresses, is whether charity signals trustworthiness. The utility costs of a donation are lower for someone who has altruistic preferences, and really cares about the goals of the charity, than for a selfish person. As more altruistic subjects are most likely also more trustworthy, charity could play the role of a signal of trustworthiness. Fehrler and Kosfeld (2010), for example, show that subjects who identify themselves with the altruistic goals of an NGO are on average substantially more trustworthy than subjects who do not and receive higher transfers from trustors. Elfenbein et al. (2010) who analyze data from Ebay find that sellers who commit to donate a share of the selling price of their product to charity sell more than sellers who do not, controlling for product quality and the reputation of the seller. This result is more pronounced for sellers who are relatively new in the market and could not yet build up a reputation of trustworthiness.

Signaling trustworthiness would not be a good explanation for private charity if the latter was mainly anonymous. Glazer and Konrad (1996), who discuss the role of charity as a signal of wealth, address this concern and present data on donations to several American universities and orchestras. These organisations received less than $1.3 \%$ of their donations anonymously. In addition, they persent data from a large university which reports donors by brackets of donation levels. The university publishes a list of donors who donate between $\$ 500$ and $\$ 999$, another list for donations in the range $\$ 1,000$ to $\$ 4,999$, and so on. Glazer and Konrad observe a bunching of donations right above the thresholds. Harbaugh (1998) provides similar evidence for donations to a law school, and Sieg and Zhang (2009) who analyze more recent data find that people who give to charity particularly value private benefits which are associated with high social prestige such as invitations to charity dinner parties. These results suggest that donors at least partly donate for the signal's sake.

This paper studies the role of charity as a signal of trustworthiness in a laboratory experiment in which subjects play a standard trust game (Berg et al. 1995). Before the game is played, the trustees have the opportunity to publicly donate money to Amnesty International (AI). At this stage they know about the game that will be played afterwards and can, thus, make their choice strategically. The main finding is that donating raises the other players' beliefs about the trustee's trustworthiness. As a consequence, donors receive 
substantially higher transfers. Moreover, I find that donors are, indeed, more trustworthy.

The paper proceeds with the experimental design in section 2, with the presentation of the results in section 3 , and the conclusion in section 4 .

\section{Experimental Design}

Half of the subjects are assigned the role of trustors the other half of trustees. Trustors receive an initial endowment of 10 points, trustees of 14 points. The trustees start by making a donation of 4 points to Amnesty International or by choosing not to donate 1

After this stage the subjects play a trust game. Trustors can transfer $0,2,4,6,8$ or 10 points to the trustees. They can make their transfer decision conditional on the whether the trustee has donated or not. The transfers are tripled. The trustees can then send back any integer amount of points from the points they dispose of after receiving the transfer back to the trustor. Backtransfers are not tripled. The experiment ends after the backtransfers are made. It consists of only one round.

To see whether the donors care about the NGO, they are asked about their identification with AI in a brief questionnaire before the instructions to the experiment were distributed. It includes questions like "Do you do sports?", "Do you play an instrument?" and the question "Do you strongly identify yourself with the goals of Amnesty International?". Subjects have to answer "Yes" or "No". The questionnaire is designed to give the subjects the impression that they take part in a small socioeconomic survey. This makes it unlikely that they expect their answers to play a role in the experiment.

\section{Procedural Details}

The experiment was conducted together with other experiments. In two sessions (1 and 2 ), the subjects had already participated in another experiment and participated in a third after this experiment. 2 In sessions 3 and 4 , this experiment was the first and the subjects only participated in one more experiment. In these sessions the subjects were not informed that there would be a second experiment until the first was over. Spill-over effects from the second experiment were thus impossible in sessions 3 and 4 . In sessions 1 and 2, one

\footnotetext{
${ }^{1}$ The donations are indeed transfered to AI after the experiment and this was communicated in the written instructions of the experiment and orally repeated before the start of the experiment.

${ }^{2}$ The experiment they played before playing this experiment was also a variant of a trust game but with different pairs of subjects and changed roles of trustor and trustee.
} 
point was worth 0.5 CHF, in sessions 3 and 4, 0.8 CHF. Because of these differences between sessions 1 and 2, and session 3 and 4, the data from sessions 3 and 4 are analyzed separately as a robustness check of the results obtained with the pooled data set.

The strategy method is used, which means that trustors make two transfer decisions, one for each type of trustee. Trustees make six backtransfer decisions, one for every possible trustor's transfer 3

A total of 130 subjects participated in the experiment. It was conducted in the laboratory of the Institut für Empirische Wirtschaftsforschung (IEW) at the University of Zurich.4

\section{Results}

The number of donors is high. Out of 65 trustees, 45 donate and 20 do not.

Trustors were asked about their beliefs regarding backtransfers from donors and nondonors for all possible transfer levels. Table 1 and Figure 1 show that they believe to receive substantially higher backtransfers from donors. The expected backtransfer-transfer ratios (Table 1) are significantly different at the 1\% level (adjusted Wald test).

Table 1: Expected backtransfer-transfer ratio for positive transfers. ${ }^{a}$

\begin{tabular}{lcc} 
& Transfer & (Std. Err.) \\
\hline from donors & 1.19 & $(0.08)$ \\
from non donors & 0.73 & $(0.09)$ \\
\hline $\mathrm{N}$ & & 65 \\
\hline
\end{tabular}

${ }^{a}$ Standard errors are cluster adjusted.

Regressing beliefs on transfers gives significantly different slopes for the linear fits in Figure 1 (at the 5\% level, adjusted Wald test). In these regressions there are four observations from every trustor, one for every possible transfer level. This is taken into account in the

\footnotetext{
${ }^{3}$ The use of the strategy method in a trust game has been shown to lead to lower trustworthiness as compared to the "game" method (Casari and Cason 2009). Trust levels were however unaffected by the choice of method. A point which is often made is that the strategy method elicits cooler thinking (e.g., Zizzo 2010). In the context of this experiment, this would rather lead to an attenuation of the effect of the donation on trust than to the contrary, and thus pose a harder test for the hypothesized effect.

${ }^{4}$ The treatments were programmed with zTree (Fischbacher 2007).
} 
estimation of the standard errors by treating these four observations as one cluster each. Nonlinear fits to the data show that the assumption of a linear relation is unproblematic (see Figures 3 and 4 in the appendix).

Figure 1: Beliefs of trustors about backtransfers from different trustees (65 obs).

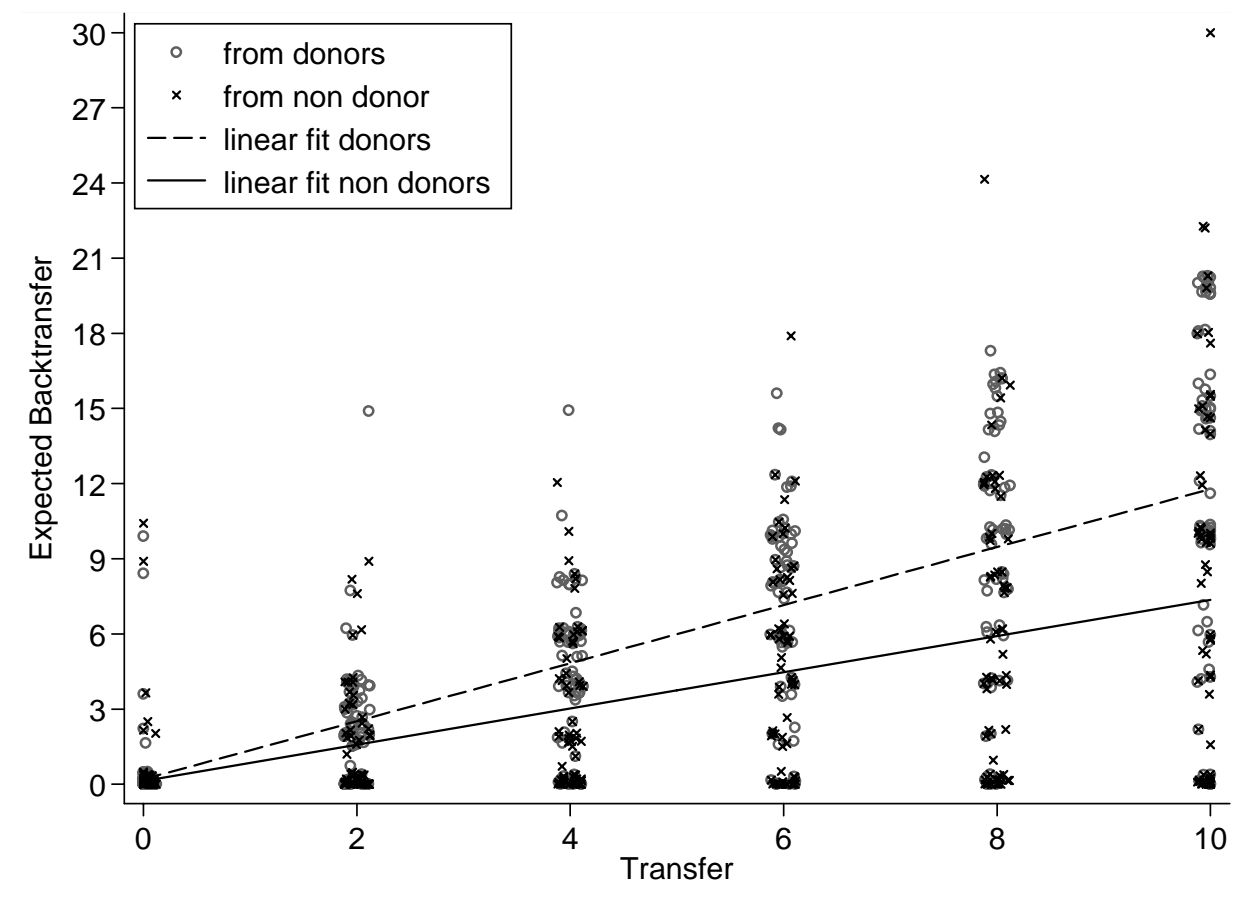

Table 2: Transfers to and backtransfer-transfer ratio of different types of trustees.

\begin{tabular}{lccc} 
& Transfer (Std. Err.) & & $\frac{\text { Backtransfer }}{\text { Transfer }}$ (Std. Err.) \\
\hline to donors & $4.98(0.45)$ & from donors & $0.98(0.12)$ \\
to non donors & $2.49(0.44)$ & from non donors & $0.67(0.14)$ \\
\hline N (trustors) & 65 & $\mathrm{~N}$ (trustees) & 65 \\
\hline
\end{tabular}

${ }^{a}$ Standard errors for the backtransfer-transfer ratio are cluster adjusted.

The transfer levels to the different types of trustees reflect these beliefs. Trustors transfer double to donors than to non-donors, 4.98 and 2.49 points respectively. These transfers are significantly different from each other (at the $1 \%$ level, t-test). As transfers are tripled, trustees who donate receive 7.5 points more than non-donors, which is a huge difference. The 
result indicates that charity works well as means to convince others of one's trustworthiness.

Moreover, trustors' beliefs are quite accurate. Figure 2 presents the actual backtransfer choices of the different types of trustees. Donors do indeed transfer back more than nondonors. The backtransfer-transfer ratios (Table 2) are significantly different at the $10 \%$ level (adjusted Wald test). However, the slopes of linear fits to the data in Figure 2 are not significantly different from each other (at the $10 \%$ level, adjusted Wald test) $!^{5}$

Figure 2: Trustworthiness of different donor types.

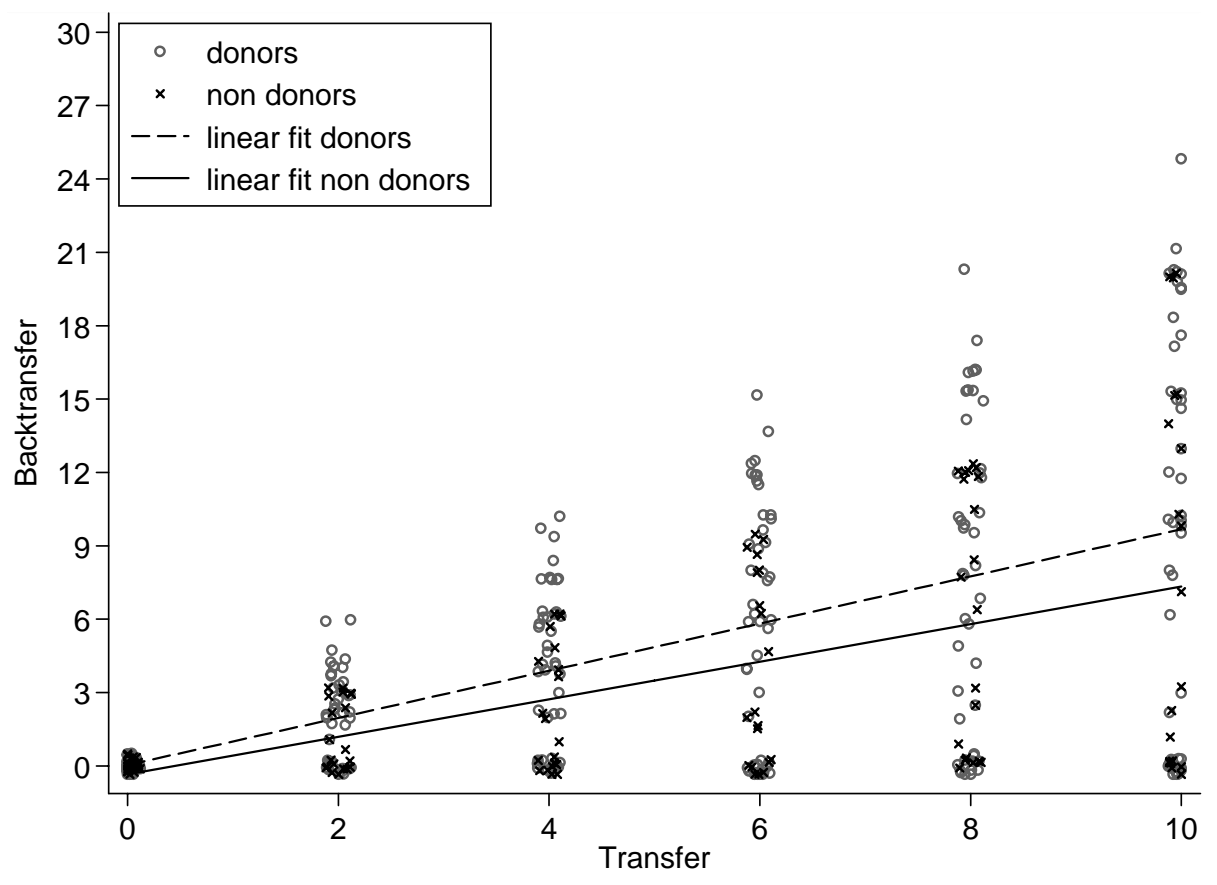

From all 130 participants 45 (25 of them trustors) indicate in the questionnaire that they identify themselves strongly with the goals of AI. As expected, substantially more subjects donate to AI, which might be due to the signaling character of the donation. From the 25 trustees who indicate that they identify themselves strongly with the goals of AI 21 donate, from the remaining 40 non donating trustees only 24. These shares are statistically different at the $5 \%$ level $\left(\chi^{2}\right.$-Test). Of those who donate, those who also identify themselves with AI have a higher backtransfer-transfer ratio (1.03 as compared to 0.93). However, this difference is not statistically significant at $10 \%$ level (adjusted Wald test).

\footnotetext{
${ }^{5}$ In this regression again there are four observations from every subject, one for each possible transfer level. As before, this is taken into account in the estimation of the standard errors by treating these four observations as one cluster each.
} 
Table 3: Identification with AI and the decision to donate.

\begin{tabular}{lcc|l} 
& Identification & No Identification & $\mathrm{N}$ \\
\hline Donor & 21 & 24 & 45 \\
Non donor & 4 & 16 & 20 \\
\hline $\mathrm{N}$ & 25 & 40 & 65 \\
\hline
\end{tabular}

Analyzing the data from sessions 3 and 4 separately as a robustness check does not change the main results (see appendix), i.e., the difference between the conditions in sessions 1 and 2 , and sessions 3 and 4 do not influence the subjects' behavior in an important way ${ }_{6}^{6}$

\section{Conclusion}

In this study, the potential of prosocial behavior in general and charity in particular as signals of trustworthiness is studied in a laboratory experiment. The main finding is that trustees who publicly donate to Amnesty International (AI) are expected to be more trustworthy and receive substantially higher transfers in a trust game. Trustors transfers are on average twice as high to donors than to non-donors. Indeed, donors are more trustworthy than subjects who do not donate. Charity can, therefore, serve as a signal of trustworthiness.

Partly, subjects care about their reputation of behaving prosocially merely for the social esteem that comes along with it. This has been shown in several studies. In other settings, like in this experiment, a reputation of being a prosocial person also comes with substantial monetary benefits. This strengthens the reputational motive for prosocial behavior as described, e.g., in Bénabou and Tirole (2006) or Elligsen and Johannesson (2008). Moreover, the results are consistent with costly signaling explanations of the evolution of cooperation (e.g., Gintis et al. 2001).

\footnotetext{
${ }^{6}$ Not all the results are unchanged w.r.t. their level of statistical significance (see appendix for details).
} 


\section{References}

Albert, M., W. Güth, E. Kirchler, and B. Maciejovsky (2007): “Are We Nice(r) to Nice(r) People? An Experimental Analysis," Experimental Economics, 10(1), 53-69.

Alexander, R. D. (1987): The Biology of Moral Systems. Aldine de Gruyter.

Andreoni, J. (1990): "Impure Altruism and Donations to Public Goods: A Theory of Warm-Glow Giving?," Economic Journal, 100(401), 464-77.

Andreoni, J., And R. Petrie (2004): "Public goods experiments without confidentiality: a glimpse into fund-raising," Journal of Public Economics, 88(7-8), 1605 - 1623.

Ariely, D., A. Bracha, and S. Meier (2009): "Doing Good or Doing Well? Image Motivation and Monetary Incentives in Behaving Prosocially," American Economic Review, $99(1), 544-55$.

Barclay, P., and R. Willer (2007): "Partner Choice Creates Competitive Altruism in Humans," Proceeding of The Royal Society B, 274, 749-753.

Berg, J., J. Dickhaut, and K. MCCABe (1995): "Trust, Reciprocity, and Social History," Games and Economic Behavior, 10(1), 122-142.

Bénabou, R., And J. Tirole (2006): "Incentives and prosocial behaviour," American Economic Review, 96(5), 1652-1678.

Bolle, F., And J. Kaehler (2007): "Introducing a Signaling Institution: An Experimental Investigation," Journal of Institutional and Theoretical Economics, 163(3), 428-447.

CAsari, M., And T. N. CASOn (2009): "The strategy method lowers measured trustworthy behavior," Economics Letters, 103(3), 157-159.

Dana, J., D. M. Cain, and R. M. Dawes (2006): "What You Don't Know Won't Hurt Me: Costly (but Quiet) Exit in Dictator Games," Organizational Behavior and Human Decision Processes, 100(2), 193 - 201.

Diekmann, A., And W. Przepiorka (2008): "Signaling Trustworthiness: Evidence from Lab Experiments," Mimeo.

Elfenbein, D. W., R. Fisman, and B. McManus (2010): "Charity as a Substitute for Reputation: Evidence from an Online Marketplace," SSRN Discussion Paper No. 1615120. 
Ellingsen, T., and M. Johannesson (2008): "Pride and Prejudice: The Human Side of Incentive Theory," American Economic Review, 98(3), 990-1008.

Fehrler, S., And M. Kosfeld (2010): "Can You Trust the Good Guys?," Paper presented at the AEA Annual Meeting 2010.

FischBACHER, U. (2007): "z-Tree: Zurich toolbox for ready-made economic experiments," Experimental Economics, 10(2), 171-178.

GÄChter, S., And E. Fehr (1999): "Collective Action as a Social Exchange," Journal of Economic Behavior $\&$ Organization, 39(4), 341 - 369.

Gintis, H., E. A. Smith, and S. Bowles (2001): "Costly Signaling and Cooperation," Journal of Theoretical Biology, 213, 103-119.

Glazer, A., And K. A. Konrad (1996): "A Signaling Explanation for Charity," American Economic Review, 86(4), 1019-1028.

Harbaugh, W. T. (1998): "The Prestige Motive for Making Charitable Transfers," The American Economic Review, 88(2), 277-282.

Milinski, M., D. Semmann, and H.-J. Krambeck (2002): "Donors to Charity Gain in Both Indirect Reciprocity and Political Reputation," Proceedings of the Royal Society of London B - Biological Sciences, 269(1494), 881-3.

NowaK, M. A., And K. Sigmund (1998): "Evolution of Indirect Reciprocity by Image Scoring / The Dynamics of Indirect Reciprocity," Nature, 393, 573-577.

Rege, M., And K. Telle (2004): "The Impact of Social Approval and Framing on Cooperation in Public Good Situations," Journal of Public Economics, 88(7-8), 1625 - 1644.

Sieg, H., And J. Zhang (2009): "The Joys of Giving and Receiving," Paper presented in the Applied Micro and Organisation Seminar at the University of Frankfurt.

Soetevent, A. R. (2005): "Anonymity in Giving in a Natural Context-a Field Experiment in 30 Churches," Journal of Public Economics, 89(11-12), 2301 - 2323.

Zizzo, D. (2010): "Experimenter Demand Effects in Economic Experiments," Experimental Economics, 13(1), 75-98. 


\section{Appendix}

The appendix presents figures which show that the assumption of a linear relation in the regressions is unproblematic, the results from sessions 3 and 4, henceforth called the reduced sample, and the instructions.7

Figure 3: Beliefs of trustors about backtransfers from different trustees (65 obs).

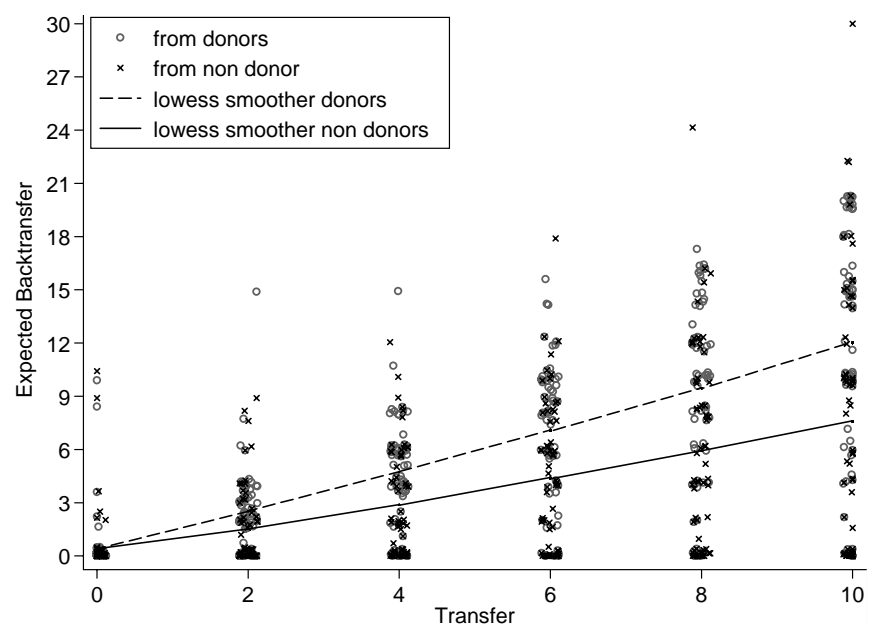

Figure 4: Trustworthiness of different donor types.

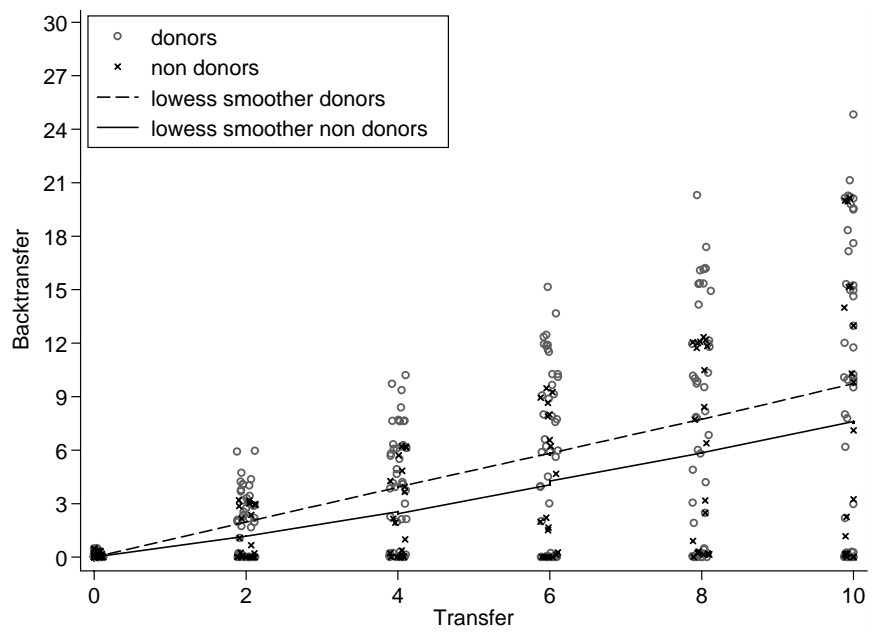

${ }^{7}$ Only instructions for trustors are presented. Instructions for trustees were very similar. The original German instructions can be obtained from the author. 
Figures 3 and 4 display the same scatterplots as Figures 1 and 2 but with lowess smoothers instead of the linear fits. They show that the assumption of a linear relation is unproblematic.

In the reduced sample, just as in the pooled sample, the expected backtransfer-transfer ratios (Table 4) are statistically different at the $1 \%$ level (adjusted Wald test). The difference in the slopes of the linear fits in Figure 5 are even more pronounced and statistically different at the $1 \%$ level (adjusted Wald test).

The difference in the transfer level (Table 5) are also significant at the $1 \%$ level (t-test), and the differences in the backtransfer-transfer ratios at the 10\% level (adjusted Wald test).

The difference in the slopes of the linear fits in Figure 6 is not significant at the $10 \%$ level (adjusted Wald test). Finally, the $\chi^{2}$ value of the test in Table 6 indicates that the Null-hypothesis of random allocation to the table cells cannot be rejected at the $10 \%$ level.

Overall, the results are very similar to the ones obtained from analyzing the pooled sample.

\begin{tabular}{lcc} 
Table 4: Expected Backtransfer-Transfer \\
Ratio for positive transfers & (reduced \\
sample). ${ }^{a}$ & & \\
& Transfer & (Std. Err.) \\
\hline from donors & 1.01 & $(0.11)$ \\
from non donors & 0.58 & $(0.13)$ \\
\hline $\mathrm{N}$ & \multicolumn{3}{c}{65}
\end{tabular}

${ }^{a}$ Standard errors are cluster adjusted

Table 5: Transfers and backtransfer-transfer ratio to and of different types of trustees (reduced sample).

\begin{tabular}{lccc} 
& Transfer (Std. Err.) & & $\frac{\text { Backtransfer }}{\text { Transfer }}$ (Std. Err.) \\
\hline to donors & $4.51(0.67)$ & from donors & $1.02(0.17)$ \\
to non donors & $2.13(0.60)$ & from non donors & $0.57(0.18)$ \\
\hline $\mathrm{N}$ (trustors) & 65 & $\mathrm{~N}$ (trustees) & 65 \\
\hline
\end{tabular}

${ }^{a}$ Standard errors for the backtransfer-transfer ratio are cluster adjusted. 
Figure 5: Expected Trustworthiness of different donor types (reduced sample).

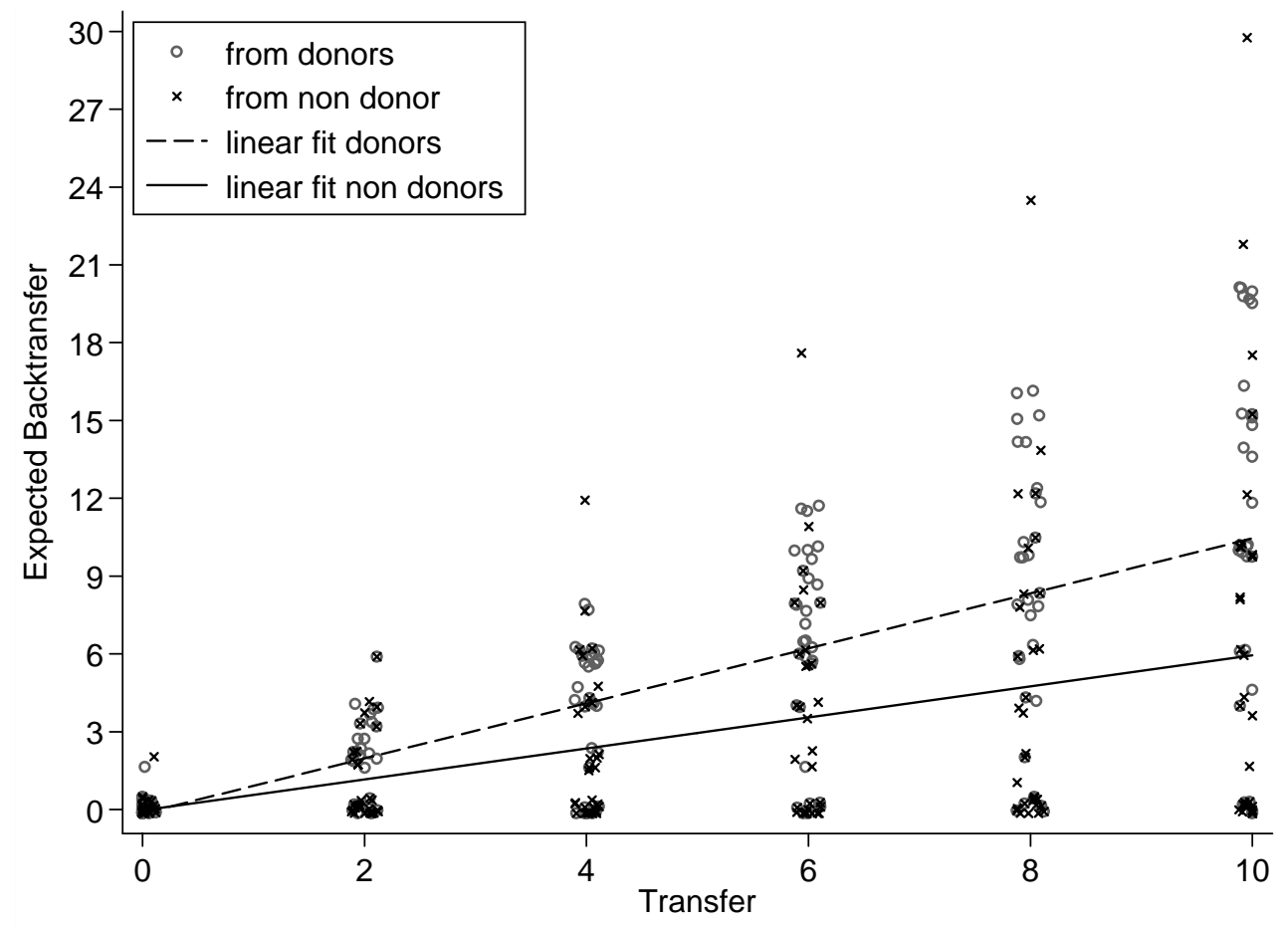

Table 6: Identification with $\mathrm{AI}$ and the decision to donate (reduced sample).

\begin{tabular}{lcc|c} 
& Identification & No Identification & $\mathrm{N}$ \\
\hline Donor & 8 & 13 & 21 \\
Non donor & 2 & 8 & 10 \\
\hline $\mathrm{N}$ & 10 & 21 & 31 \\
\hline \hline p-value $\chi^{2}$-test & & 0.31 \\
\hline
\end{tabular}


Figure 6: Trustworthiness of different donor types (reduced sample).

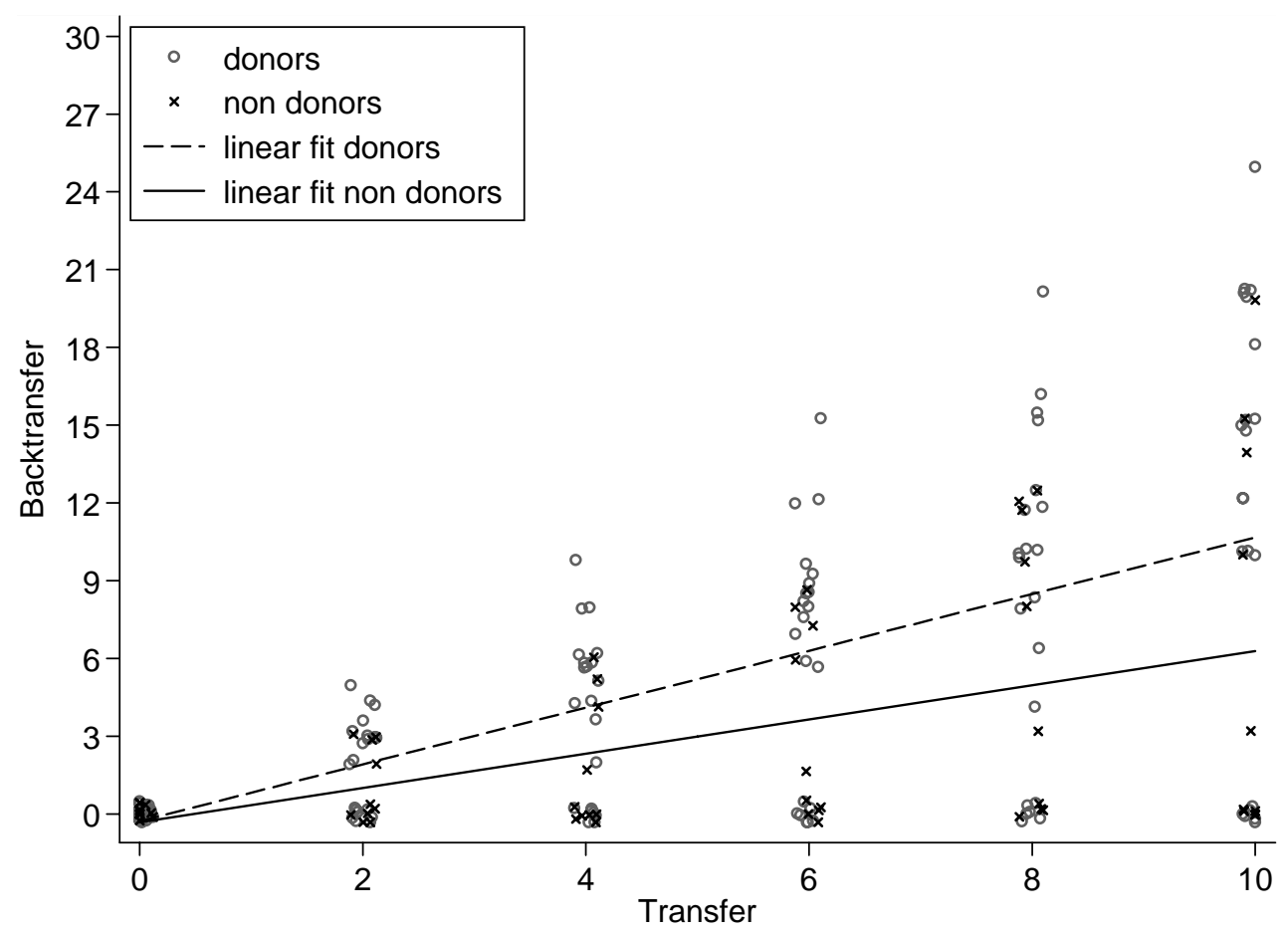




\section{Experiment : General Information for Participant A}

You will now participate in a scientific experiment.

If you carefully read the following instructions, you can earn money. How much money you will earn depends on your decisions and decisions of other participants in the experiment. It is, therefore, important to read the instructions carefully.

Please, note that it is not permitted to communicate with other participants during the experiment. If you have questions, please, direct them at us.

At the beginning of the experiment all participants receive a show-up fee of 10 CHF. During the course of the experiment you can earn points in addition to that. All points you earn are converted into Swiss Francs at the end of the experiment. The exchange rate is:

\section{Point $=0.80$ CHF .}

At the end you receive the income you have earned during the experiment plus the $10 \mathrm{CHF}$ show-up fee in cash. You will be paid out in a separate room, so that no other participant can see how much you have earned. 


\section{The Experiment}

In this experiment there are always a participant $A$ and participant B together in a group of two. No participant knows the identity of the participant who is in her group, that is, all decisions are made anonymously.

\section{You are participant $A$.}

At the beginning participant $\mathrm{B}$ receives 4 points. He can donate them to Amnesty International or keep them. In case of a donation, all the points that are donated in the experiment are summed up, converted into Swiss Francs and transferred to Amnesty International.

You, as a participant A, can make your decisions dependent on whether B has donated or not.

Participants A and B receive 10 points. You, as participant A, can now transfer $0,2,4,6,8$ or 10 points to B. This transfer is tripled. Participant B can then transfer back any amount out of the points he disposes of to you.

The income of both participants is determined in dependence on your and B's decisions as follows:

You, as participant A, earn

0 - Your transfer to B +Participant B's backtransfer to you.

\section{Participant B earns}

$10+3 \times$ Your transfer to B - B's backtransfer to you +4 (in case B does not donate)

You can make your decision conditional on whether B has donated or not. You have to make a decision for both cases.

Which of the two cases is relevant for the pay-off will be determined by the actual decision (to donate or not) of the participant $B$ you are matched with. 
After you have made your transfer decisions, participant B learns how much you have transferred and makes his transfer decision.

After all participants have made their decisions, the experiment ends. Your income will be paid out privately, so that the other participants do not know how much you have earned.

\section{Control Questions}

Please, answer the following control questions. Your answers do not influence the pay-offs of the experiment but only serve to check whether everybody understands the experiment. When you have finished, please, raise your hand, so that we can check your answers.

Question 1: You are Participant A. How many transfer decisions are you going to make in this experiment?

Question 2: You are Participant A. What determines which of your decisions becomes relevant for the pay-offs?

Question 3: You are Participant A. Assume, your pay-off relevant transfer to B is 4 points, Participant B has donated and her backtransfer to you is 6 points.

What is your income?

What is participant B's income?

Question 4: You are Participant A. Assume, your pay-off relevant transfer to B is 6 points, Participant B has not donated and her backtransfer to you is 0 points.

What is your income?

What is participant B's income?

Question 5: You are Participant A. Assume, your pay-off relevant transfer to B is 10 points, Participant B has donated and her backtransfer to you is 20 points.

What is your income?

What is participant B's income?

\section{Do you have questions?}

